\title{
Evaluation of tribological properties of selected engine oils during operation of the friction pairs of steel-on-steel
}

\author{
Marcin Barszcz ${ }^{1, *}$, Jerzy Józwik ${ }^{2}$, Krzysztof Dziedzic ${ }^{3}$, and Kamil Stec ${ }^{1}$ \\ ${ }^{1}$ Lublin University of Technology, Fundamentals of Technology Faculty, Department of Fundamental of Technology, 38 \\ Nadbystrzycka Street, 20-618 Lublin, Poland \\ ${ }^{2}$ Lublin University of Technology, Mechanical Engineering Faculty, Department of Production Engineering, 36 Nadbystrzycka \\ Street, 20-618 Lublin, Poland \\ ${ }^{3}$ Lublin University of Technology, Electrical Engineering and Computer Science Faculty, Institute of Computer Science, \\ 36B Nadbystrzycka Street, 20-618 Lublin, Poland
}

\begin{abstract}
The paper includes an assessment of the tribological properties of mineral and synthetic Lotos oil marked SAE $15 \mathrm{~W} / 40$ and SAE $5 \mathrm{~W} / 40$ at ambient temperature and $100^{\circ} \mathrm{C}$. The evaluation was based on the analysis of the tribological properties of friction couple consumables. Tribological tests were performed using the Anton Paar THT 1000 high temperature tribotester according to ASTM G133. Tribological properties were investigated using the "ball on disc" method. The change of friction coefficient, friction couple temperature, volume wear of samples and counter-samples and Hertz stresses were evaluated. In addition, hardness tests of the friction couple materials as well as surface roughness before and after friction were performed. On the basis of tribological studies, it was noted that Lotos Synthetic $5 \mathrm{~W} / 40$ oil has better cooling properties compared. For both oils the coefficient of friction was lower at ambient temperature than at $100{ }^{\circ} \mathrm{C}$. The highest value of volume wear of the sample was noted for the combination lubricated with Mineral Oil $15 \mathrm{~W} / 40$ at $100{ }^{\circ} \mathrm{C}\left(0.0143 \mathrm{~mm}^{3}\right)$ while for counter-sample lubricated with synthetic oil at ambient temperature $\left(0.0039 \mathrm{~mm}^{3}\right)$. The highest sample wear coefficient was recorded for the mineral oil lubricated at temperature of $100{ }^{\circ} \mathrm{C}\left(3.585^{*} 10^{-7} \mathrm{~mm}^{3} / \mathrm{N} / \mathrm{m}\right)$ while for counter-sample lubricated with synthetic oil at ambient temperature $\left(9.8768^{*} 10^{-8} \mathrm{~mm}^{3} / \mathrm{N} / \mathrm{m}\right)$. The Hertz stress for each test couple had a value of $1.787 \mathrm{GPa}$
\end{abstract}

\section{Introduction}

Wear of machine and equipment parts resulting from friction has always been a problem for engineers involved in the design and selection of materials for friction couples. It determines the durability of the whole machine or device, and the period of failure-free operation, which ultimately affects the quality of their work [1].

In many cases, the elements of machines and devices parts cooperating in terms of friction work in very heavy and variable conditions. This involves the use of materials of appropriate utility properties, the use of specialized surface treatment methods, lubricants and lubrication techniques. This certainly has a significant impact on the work of tribological systems and their suitability for specific working conditions. Therefore, the current work and research is aimed at finding new construction and material solutions that reduce the wear and production and operation costs of machines and equipment [2-6].

One of the methods to reduce the friction and wear of the cooperating elements is to use suitable lubricants. In recent years, intense works have been carried out to improve their properties. Many researchers are attempting to introduce various additives to engine oils. Authors of many works have confirmed that adding nanoparticles to the oil leads to improved tribological properties. Nanoparticles such as carbon nanoparticles and, in particular, fullerene nanoparticles [7] diamond nanoparticles [8], nanotubes [9] and graphene nanoparticles $[10,11]$ were introduced. These exhibited promising properties thanks to the ease of shear of individual layers. Nanofulerenes and nanotubes showed a reduction in friction and wear from macro- to nanoscale, due to the formation of tribofilm. Research with addition of oxides nanoparticles were carried out by the following authors: copper oxides $\mathrm{CuO}[12,13,14]$, titanium dioxide $\mathrm{TiO}_{2}$ [13], silicon dioxide $\mathrm{SiO}_{2}[15]$ and metal nanoparticles, i.e. copper [16,17], iron, cobalt and their combinations [17]. According to [17], the use of $\mathrm{Cu}$ nanoparticles provides the most effective friction and wear reduction in each of the nanoparticles studied. Surface analysis indicates that the nanoparticle components have precipitated on the contact surface during the application of oils with nano-additives. In turn, the authors $[18,19]$ investigated the effect of modifying the Lotos Dynamic 0W/40 oil with the chemical treatment of MotorLife Professional. The authors of the paper [20] have noted that a suitable lubricant has an influence on the selforganization of the friction surface. In the paper [20], based

* Corresponding author: jjozwik@pwsz.chelm.pl 
on the results of the various lubricants, the authors have indicated that the wear intensity is low. According to [21], this effect of the lubricant and its properties is related to the self-organization of the surface in the friction process.

The authors of this paper and the team are engaged in the development and testing of wear resistant materials [2225]. In recent years, they have attempted to investigate the phenomenon of surface self-organization in the process of friction. As a result, basic tribological studies were carried out to determine tribological properties of mineral oil and synthetic Lotos oil marked SAE 15W/40 and SAE 5W/40 at ambient temperature and $100{ }^{\circ} \mathrm{C}$. The authors of this paper will use these oils for further research to modify and study self-organization of the friction surfaces.

\section{Experimental details}

\subsection{Research object}

Two engine oils were analyzed: Lotos Synthetic 5W/40 and Lotos Mineral 15W/40, which were subjected to tribological evaluation at ambient temperature and temperature of $100{ }^{\circ} \mathrm{C}$. The temperature of $100{ }^{\circ} \mathrm{C}$ was selected because it is similar to the operating temperature of the engine oil. The specifications for engine oils are shown in Tables 1 and 2.

Table 1. Specification of synthetic engine oil Lotos Synthetic $5 \mathrm{~W} / 40$.

\begin{tabular}{|l|c|}
\hline Parameter name & Parameter \\
\hline API quality class & SN/CF \\
\hline SAE viscosity grade & $5 \mathrm{~W} / 40$ \\
\hline Kinematic viscosity at $100^{\circ} \mathrm{C}$ & 13.7 \\
\hline Viscosity index, min & 165 \\
\hline Flow temp., max $\left({ }^{\circ} \mathrm{C}\right)$ & -36 \\
\hline HTHS viscosity at $150^{\circ} \mathrm{C}$ & 3.6 \\
\hline Basic number $(\operatorname{mgKOX})$ & 10 \\
\hline Evaporation, NOACK test, $\max$ & 11.5 \\
\hline
\end{tabular}

Table 2. Specification of mineral engine oil Lotos 15W/40.

\begin{tabular}{|l|c|}
\hline Parameter name & Parameter \\
\hline API quality class & $\mathrm{SJ} / \mathrm{CF}$ \\
\hline SAE viscosity grade & $15 \mathrm{~W} / 40$ \\
\hline Kinematic viscosity at $100^{\circ} \mathrm{C}$ & 15 \\
\hline Viscosity index, min & 130 \\
\hline Flow temp., $\max \left({ }^{\circ} \mathrm{C}\right)$ & -30 \\
\hline HTHS viscosity at $150{ }^{\circ} \mathrm{C}$ & - \\
\hline Basic number $(\mathrm{mgKOX})$ & 6.9 \\
\hline Evaporation, NOACK test, $\max$ & - \\
\hline
\end{tabular}

In order to carry out the study and evaluation of the tribological properties, elements of the friction couple in the form of samples and counter-samples were prepared.
The samples were made of C45 steel, the chemical composition of which is shown in Table 3. They were prepared in the form of a disc with dimensions of $\varphi 30 \times 5 \mathrm{~mm}$. The samples thus prepared were subjected to heat treatment in the form of hardening and high tempering. Tempering was performed at temperatures between $820^{\circ} \mathrm{C}$ and $860{ }^{\circ} \mathrm{C}$. Water was used as a cooling center. In order to remove the stresses caused by hardening, the samples were subjected to tempering at temperatures of $550{ }^{\circ} \mathrm{C}$ to $660{ }^{\circ} \mathrm{C}$. Prior to tribological studies, the sample surfaces were ground.

Table 3. C45 steel chemical composition.

\begin{tabular}{|c|c|c|c|c|}
\hline $\mathbf{C}$ & $\mathbf{M n}$ & $\mathbf{S i}$ & $\mathbf{P}$ & $\mathbf{S}$ \\
\hline $0.42-0.5$ & $0.5-0.8$ & $0.1-0.4$ & $\max 0.04$ & $\max 0.04$ \\
\hline $\mathbf{C r}$ & $\mathbf{M o}$ & $\mathbf{N i}$ & $\mathbf{C u}$ & $\mathbf{A l}$ \\
\hline $\max 0.3$ & $\max 0.1$ & $\max 0.3$ & $\max 0.3$ & $\max 0.5$ \\
\hline
\end{tabular}

The counter-samples used in the tests were made of 100Cr6 bearing steel. The chemical composition of the steel is shown in Table 4. The diameter of the beads was $6 \mathrm{~mm}$.

Table 4. 100Cr6 steel chemical composition.

\begin{tabular}{|c|c|c|c|}
\hline $\mathbf{C}$ & $\mathbf{M n}$ & $\mathbf{S i}$ & $\mathbf{P}$ \\
\hline $0.95-1.1$ & $0.25-0.45$ & $0.15-0.35$ & $\max 0.025$ \\
\hline $\mathbf{S}$ & $\mathbf{C r}$ & $\mathbf{N i}$ & $\mathbf{C u}$ \\
\hline $\max 0.025$ & $1.3-1.65$ & $\max 0.3$ & $\max 0.3$ \\
\hline
\end{tabular}

\subsection{Tribological studies}

Tribological studies were carried out using the Anton Paar THT 1000 high temperature tribotester according to ASTM G133, Fig. 1. It allows to determine the coefficient of friction of the co-operating materials, their working temperature at the contact point, and the amount of wear depending on the applied surface pressure, slip velocity of the shield and sliding distance. It is equipped with heating elements so that one can conduct research at temperatures up to $1000{ }^{\circ} \mathrm{C}$. The "ball on disc" association was used to study tribological properties, Fig. 2.

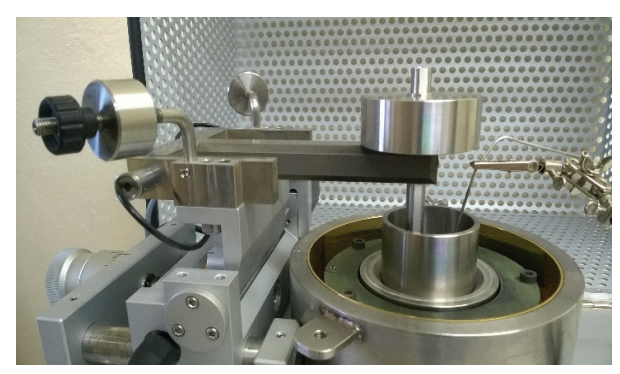

Fig. 1. Tribotester THT 1000.

Tribological studies were conducted at a steady slip velocity of the shield (sample) of $0.4 \mathrm{~m} / \mathrm{s}$ and an $F_{n}=20 \mathrm{~N}$ load at a radius of $10 \mathrm{~mm}$. The study was carried out at ambient temperature and temperature of 
$100{ }^{\circ} \mathrm{C}$ for two engine oils, Lotos Synthetic 5W/40 and Mineral Oil 15W/40. In each test, the friction couple was placed in a container and immersed in equal volume of oil $(50 \mathrm{ml})$. The friction coefficient, frictional force and friction couple temperature were recorded during the tests. The temperature was measured with a thermocouple of $1 \mathrm{~mm}$ from the friction surface. The sampling frequency was $10 \mathrm{~Hz}$.

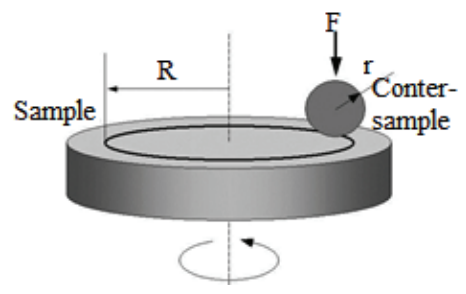

Fig. 2. Friction couple; $\mathrm{R}$ - radius of friction, $\mathrm{r}$ - ball radius, $\mathrm{F}$ - normal force.

After the tribological studies, volume wear of samples and counter-samples was determined. Volume wear of the samples was calculated as the product of the mean value of the sample wear area and the circumference of the friction wheel formed in the test as described by the formula (1):

$$
V_{f}=A \cdot L
$$

where: $V_{f}$ - volume wear, $A$ - mean value of the sample wear, $L-$ friction circumference.

The volume wear of counter-samples was calculated using the following formulas (2 and 3 ):

$$
\begin{gathered}
V=\frac{\pi h^{2}}{3}(3 r-h) \\
h=r-\sqrt{r^{2}-\left(\frac{d}{2}\right)^{2}}
\end{gathered}
$$

where: $r$ - ball radius, $d$ - ball wear diameter, $h$ - ball wear height.

\subsection{Hardness tests}

Hardness tests were performed using a Rockwell hardness tester. The $\mathrm{C} 45$ steel samples were subjected to heat treatment using a $\mathrm{C}$ scale. A $120^{\circ}$ diamond tipped indentation probe was used which was loaded with a $98 \mathrm{~N}$ pre-force and a total of $1471 \mathrm{~N}$. For each sample, 5 measurements were performed and then the arithmetic mean of the results was calculated.

\subsection{Surface roughness tests}

Surface roughness testing of the samples was carried out before and after tribological studies. They were made using Surtronic $3+$ needle gauge. The tests were perpendicular to the direction of the machining and friction traces. They were made at an elementary length of $4 \mathrm{~mm}$ with an accuracy of $0.02 \mu \mathrm{m}$. Surface roughness was determined on the basis of the average arithmetic deviation of the profile from the Ra average line. The test was repeated 5 times for each sample and then the arithmetic mean of the results was calculated.

\section{Results and discussion}

The hardness of the samples after heat treatment (hardening and high tempering) varied between 49-53 HRC and 62-63 HRC. In turn, the surface roughness parameter Ra of samples before the tribological studies varied within the range of $0.32-0.46 \mu \mathrm{m}$

After the hardness and surface roughness tests, tribological studies were performed. They were conducted in order to evaluate the tribological properties of the two mineral oils Lotos Mineral 15W/40 and Lotos Synthetic 5W/40 at ambient temperature and $100{ }^{\circ} \mathrm{C}$. One of the values that were analyzed during the tribological tests was the temperature of the test compound. Fig. 3 shows a graph showing the temperature distribution for friction couples lubricated with mineral oil Lotos Mineral 15W/40 and Synthetic $5 \mathrm{~W} / 40$ oil at ambient temperature. By analyzing the graph, it can be seen that the temperature of the friction couple (under accepted operating conditions) when lubricated with mineral oil Lotos Mineral 15W/40 is higher than in case of lubrication with synthetic oil Lotos Synthetic $5 \mathrm{~W} / 40$. The difference is about $4{ }^{\circ} \mathrm{C}$. In the case of synthetic oil Lotos Synthetic 5W/40, as the sliding distance increases, the temperature of the contact is increasing.

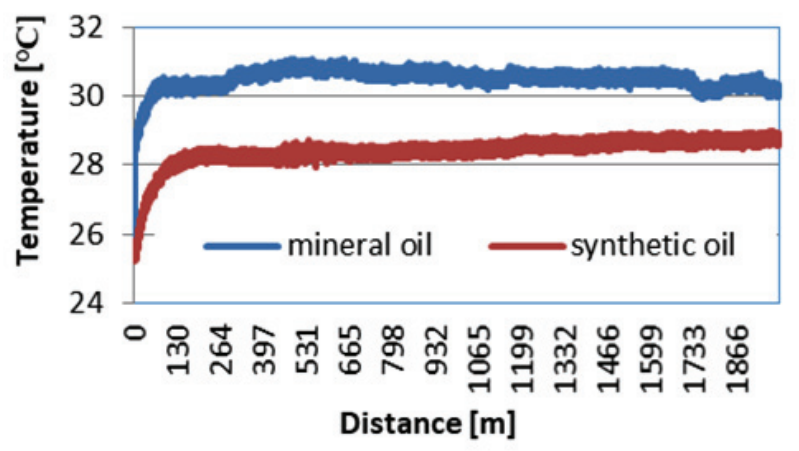

Fig. 3. Temperature distribution for couple lubricated with Lotos mineral oil $15 \mathrm{~W} / 40$ and synthetic $5 \mathrm{~W} / 40$ Lotos oil at ambient temperature.

By analyzing the graph shown in Figure 4, some similarities can be noted as with ambient temperature lubrication. Therefore, the temperature of the combination of lubricants with mineral oil Lotos Mineral 15W/40 is also higher than in case of lubrication with synthetic oil Lotos Synthetic $5 \mathrm{~W} / 40$. The difference is around $11^{\circ} \mathrm{C}$. In both cases, the temperature at the beginning of the work increases to $101{ }^{\circ} \mathrm{C}$ and then decreases, which is an evidence of the lapping process that occurs in the initial phase of the test. Then the temperature rises again and after about $1 / 3$ of the road it stabilizes. However, in the case of synthetic oil, the increase in temperature after stabilization was $1-2{ }^{\circ} \mathrm{C}$ higher than the initial temperature, i.e. the couple over the entire working period oscillated within the input temperature. This gives the opportunity to say that this oil well protects the molten surfaces and prevents the heat 
from precipitating during friction. On the other hand, when the mineral oil was immersed in the mixture, a temperature increase of about $10 \square$ above its initial value was observed, i.e. during the stabilization the friction couple worked at a temperature of about $110{ }^{\circ} \mathrm{C}$. The temperature difference between the two oils during stabilization was about $10^{\circ} \mathrm{C}$.

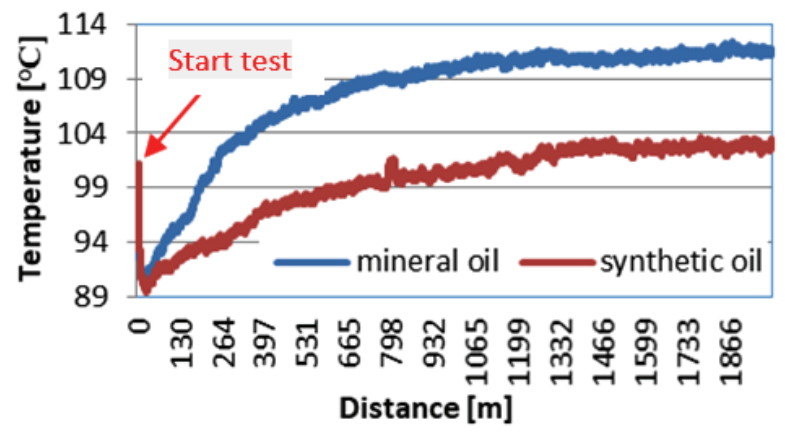

Fig. 4. Temperature distribution for the tested couple lubricated with mineral oil Lotos $15 \mathrm{~W} / 40$ and Lotos Synthetic 5W/40 at temperature of $100^{\circ} \mathrm{C}$.

The results shown in Fig. 5 describe the mean coefficient of friction obtained from laboratory tests for the test compounds at ambient temperature and $100{ }^{\circ} \mathrm{C}$. They oscillate within $0.125-0.146$. The highest coefficient of friction was achieved for the compound lubricated with Lotos Synthetic $5 \mathrm{~W} / 40$ oil at $100{ }^{\circ} \mathrm{C}(0.146)$. Referring to the temperature tests for the test compound, despite the highest friction coefficient, the temperature rose only by $2{ }^{\circ} \mathrm{C}$ from the input temperature (that is, $102{ }^{\circ} \mathrm{C}$ ). In turn, for the same input parameters, i.e. operating temperature of $100{ }^{\circ} \mathrm{C}$, for the combination lubricated with Mineral Oil $15 \mathrm{~W} / 40$, despite the lower coefficient of friction, which was 0.132 , its temperature reached $111^{\circ} \mathrm{C}$. This allows us to say that synthetic oil is much better at cooling the surface at high temperatures. The opposite is true for ambient operating conditions. The lower coefficient of friction was reached by the couple lubricated with synthetic oil, while the higher with mineral oil lubrication. The coefficient of friction for synthetic oil lubrication had the lowest value compared to the other three cases.

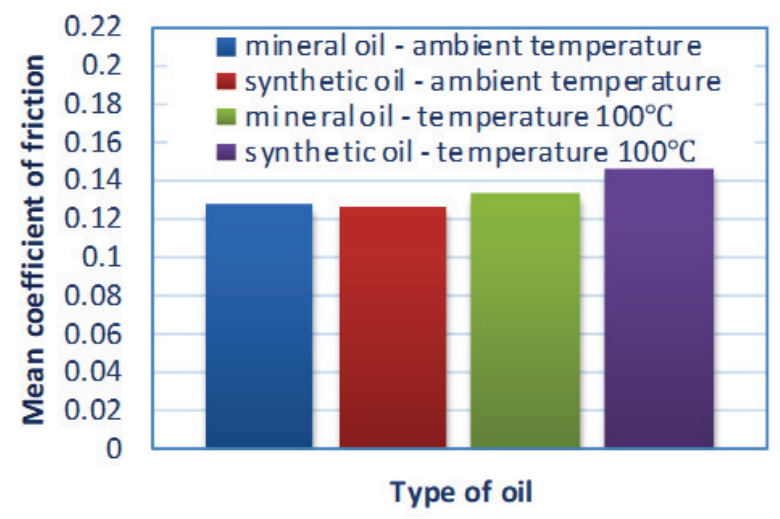

Fig. 5. Mean coefficient of friction for the testes couples.

Referring to the results of the tests shown in Fig. 6 a and Fig. 6b, which show the roughness of the surface of the sample, the differences before and after friction can be clearly observed. In the highlighted section, where there are large differences (Fig. 6b - between two vertical lines) compared to the rest of the histogram, wear of the material in the form of a friction trace can be observed. This demonstrates the microscopic effect that occurs between the sample and the counter-sample and the formation of a furrow on the surface of the sample. For the sample before friction, this cannot be observed. Therefore, it is possible to observe traces of wear during the operation of friction couple.

a)

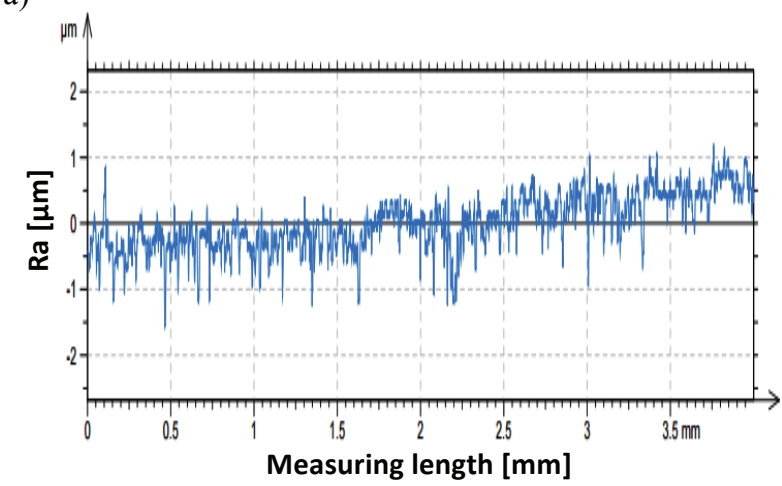

b)

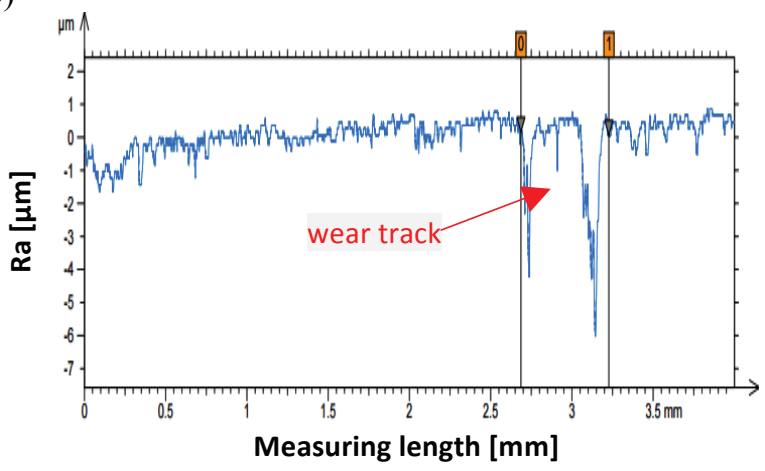

Fig. 6. Surface roughness test results: a) before friction, b) after friction.

Referring to the test results of the volume wear of the samples and the counter-samples shown in Figs. 7a and $\mathrm{b}$, there is some analogy between them for the three samples. The values are close to each other, which may indicate a steady steam consumption. Only in the case of compound lubricated with synthetic oil operating at ambient temperature, one can see a significant difference. Volume wear of this sample is the lowest in comparison to the rest of the samples tested, whereas in the case of the counter-sample it is 9 times higher than the others. The volume wear of this counter was $0.0039 \mathrm{~mm}^{3}$, while the others ranged from 0.00042 to $0.00076 \mathrm{~mm}^{3}$.

By analyzing the results of the sample wear coefficient and the counter-samples, which were presented in the graphs (Fig. 8a and Fig. 8b), the highest value in the counter-samples was obtained by a ball lubricated with synthetic oil at ambient temperature. It has reached a value $9.8768^{*} 10^{-8} \mathrm{~mm}^{3} / \mathrm{N} / \mathrm{m}$ which was nine times higher than for other counter-samples. Other values range from 1.049 to $1.68 * 10^{-8} \mathrm{~mm}^{3} / \mathrm{N} / \mathrm{m}$. In the case of samples, the highest value was obtained for the 
a)

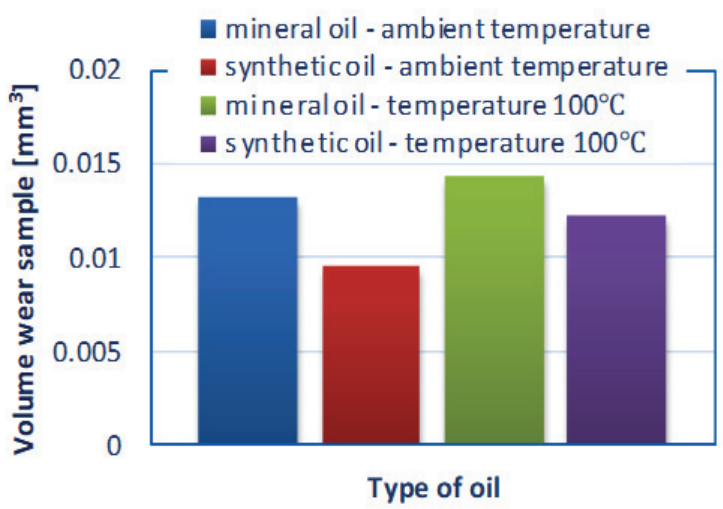

b)

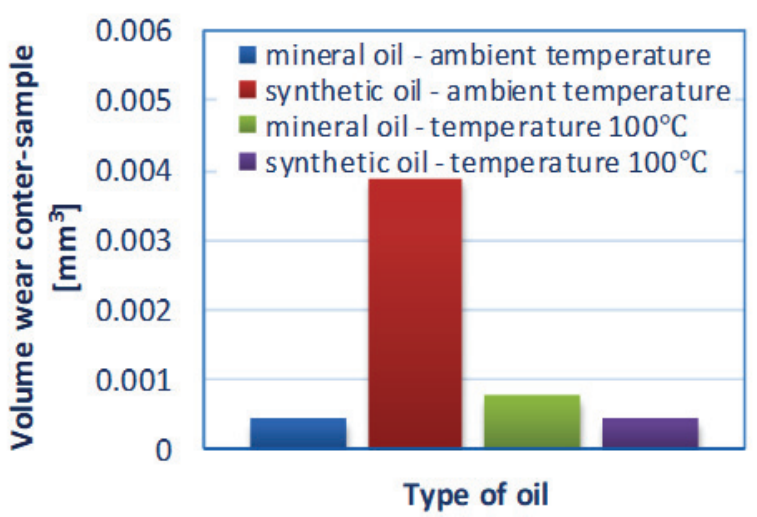

Fig. 7. Values of volume wear of a) samples, b) counter-samples.

a)

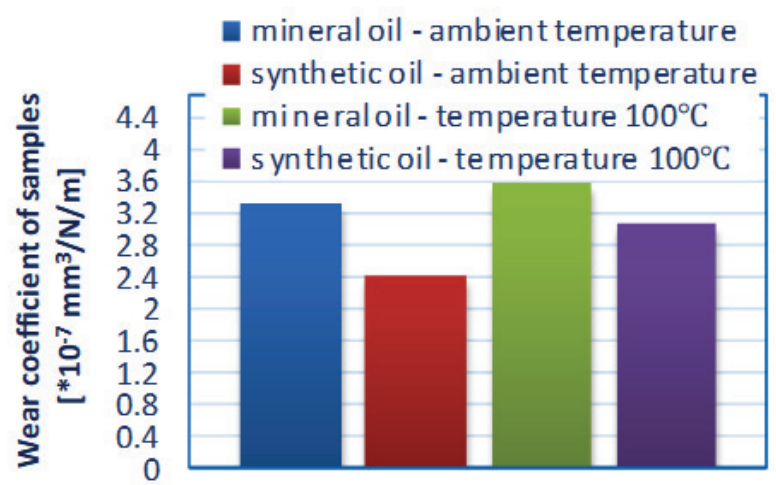

Type of oil

b)

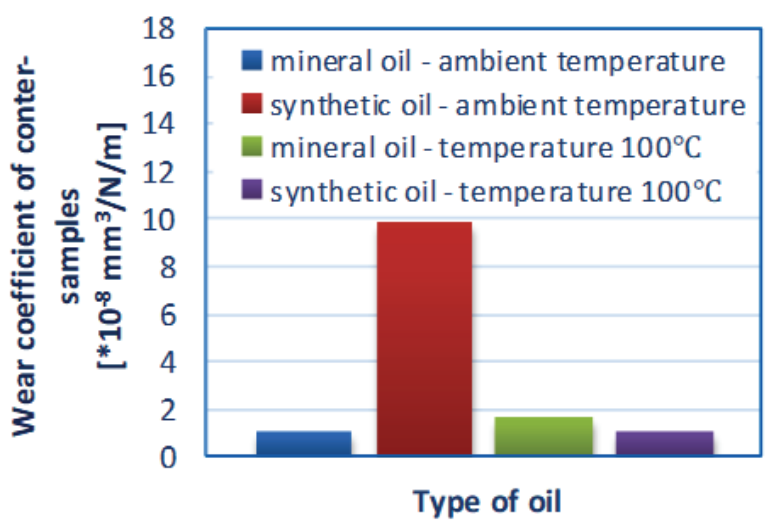

Fig. 8. Wear coefficient of a) samples, b) counter-samples. couple lubricated with mineral oil at temperature $100{ }^{\circ} \mathrm{C}$. It had a value of $3.585^{*} 10^{-7} \mathrm{~mm}^{3} / \mathrm{N} / \mathrm{m}$. The lowest value $\left(2.408 * 10^{-7} \mathrm{~mm}^{3} / \mathrm{N} / \mathrm{m}\right)$ was obtained by a sample lubricated with synthetic oil at ambient temperature. The maximum Hertz stresses for each test case were $1.787 \mathrm{GPa}$.

\section{Conclusions}

The following conclusions can be formulated on the basis of the research carried out (under the experimental conditions assumed) and the results obtained:

- Lotos Synthetic 5W/40 oil has better cooling properties compared to Lotos mineral oil 15W/40 tested.

- The average coefficient of friction for the test compounds at ambient temperature and mineral oil lubrication $15 \mathrm{~W} / 40$ was 0.182 and when lubricated with Lotos Synthetic $5 \mathrm{~W} / 40-0.125$. On the other hand, in temperature of $100{ }^{\circ} \mathrm{C}$, it was 0.133 and 0.147 respectively.

- In the tested friction couples there was a friction wear, as proved by the traces of micro-machining and chasing on the samples surfaces.

- The highest value of volume wear of the sample was noted for the combination lubricated with Mineral Oil $15 \mathrm{~W} / 40$ at $100{ }^{\circ} \mathrm{C}$, which was $0.0143 \mathrm{~mm}^{3}$. On the other hand, the lowest value amounting to $0.0096 \mathrm{~mm}^{3}$ was achieved by a sample lubricated with Lotos Synthetic $5 \mathrm{~W} / 40$ at ambient temperature.

- The values of volume wear for three counter-samples varied from 0.00042 to $0.00076 \mathrm{~mm}^{3}$. The highest value was achieved by a ball lubricated with synthetic oil at ambient temperature $\left(0.039 \mathrm{~mm}^{3}\right)$.

- The highest sample wear was recorded for the mineral oil lubricated at temperature of $100{ }^{\circ} \mathrm{C}$. It had a value of $3.585^{*} 10^{-7} \mathrm{~mm}^{3} / \mathrm{N} / \mathrm{m}$. The lowest value amounting to $2.408 * 10^{-7} \mathrm{~mm}^{3} / \mathrm{N} / \mathrm{m}$ was obtained a sample lubricated with synthetic oil at ambient temperature.

- The highest counter-sample wear was recorded when lubricated with synthetic oil at ambient temperature. It was $9.8768 * 10^{-8} \mathrm{~mm}^{3} / \mathrm{N} / \mathrm{m}$ which is 9 times higher than the other counter-samples. Other values ranged from 1.049 to $1.68 * 10^{-8} \mathrm{~mm}^{3} / \mathrm{N} / \mathrm{m}$.

- The Hertz stress for each test couple had a value of $1.787 \mathrm{GPa}$.

\section{References}

1. P. Adamiec, J. Dziubiński, Wydawnictwo Politechniki Śląskiej, Gliwice 2005

2. T. Burakowski, T. Wierzchoń, Wydawnictwo Naukowo-Techniczne, Warszawa 1995

3. J. Jozwik; M. Czwarnowski, ASTRJ, 9/28, (2015)

4. J. Jozwik, L. Semotiuk, I. Kuric, ASTRJ, 9/28, (2015)

5. E. Feldshtein, J. Józwik, S. Legutko, ASTRJ, 10/30, 2016

6. A. Glowacz, Z. Glowacz, Infrared Phys. Technol. 81, 2017 
7. B.C. Ku, Y.C. Han, J.E. Lee, J.K. Lee, S.H. Park, Y.J. Hwang, Int. J. Precis. Eng. Manuf. 11, (2010)

8. B.S. Shenoy, K.G. Binu, R. Pai, D.S. Rao, R.S. Pai, Tribol. Int. 45, (2012)

9. Y. Hwang, C. Lee, Y. Choi, S. Cheong, D. Kim, K. Lee, J. Lee, S. Kim, J. Mech. Sci. Technol. 25, (2011)

10. V. Zin, F. Agresti, S. Barison, L. Colla, E. Mercadelli, M. Fabrizio, C. Pagura, Tribol. Lett. 55, 1, (2014)

11. G. Yan-Bao, Z. Si-Wei, Lubricants, 4, (2016)

12. Y. Sayed, Akl Ahmed, A. Abdel-Rehim, A. Esraa, A. Khafagy, SAE Tech. Paper 01-0487, (2016)

13. Q. Xiaowen, J. Zhining, Y. Yulin, F. Bingli, Tribol. Int. 44, (2011)

14. M. Asrul, N.W.M. Zulkifli, H.H. Masjuki, M.A. Kalam, Procedia Eng. 68, (2013)

15. K. Prabu, B. Nalini, B. Suresh, M. Sekar, J. Achiev. Mater. Manuf. Eng. 2, (2016)

16. A. Kotnarowski, Logistyka 2, (2010)

17. J. Padgurskas, R. Rukuiza, I. Prosycevas, R. Kreivaitis, Tribol. Int. 60, (2013)

18. S. Laber, A. Laber, Tribologia 3, (2015)

19. A. Laber, Wyd. Uniwersytet Zielonogórski, (2012)

20. M. Barszcz, M. Paszeczko, K. Lenik, Arch. Metall. Mater. 60 (4), (2015)

21. I. Gershman, E.I. Gershman, A.E. Mironov, G.S. Fox-Rabinovich, S.C. Veldhuis, Entropy 18, 365, (2016)

22. M. Paszeczko, K. Dziedzic, M. Barszcz, ASTRJ 31, $10,(2016)$

23. M. Barszcz, M. Paszeczko, K. Lenik, Prace Szkoły Inżynierii Materiałowej 5, (2014)

24. M. Pashechko, J. Józwik, K. Dziedzic, M. Karolus, I. Usydus, Mater. Sci, 6, (2017)

25. J. Józwik, K. Dziedzic, I. Usydus, P. Raos, G.M. Krolczyk, Teh. Vjesn. 5, (2016) 